\title{
ADMINISTRAÇÃO DA INFORMAÇÃO PARA A INOVAÇÃO EM UMA ORGANIZAÇÃO
}

\section{GESTIÓN DE LA INFORMACIÓN PARA LA INNOVACIÓN EN UNA ORGANIZACIÓN}

\begin{abstract}
Lidiane dos Santos Carvalho - carvalho.Idn@gmail.com Doutoranda em Ciência da Informação no Instituto Brasileiro de Informação em Ciência e Tecnologia (IBICT). Professora Assistente da Universidade Federal do Estado de Rio de Janeiro (UNIRIO).

Clóvis Ricardo Montenegro de Lima - clovis.mlima@uol.com.br Pós-doutor em Ciência da Informação pelo Instituto Brasileiro de Informação em Ciência e Tecnologia (IBICT). Pesquisador adjunto do IBICT.
\end{abstract}

\begin{abstract}
RESUMO
Introdução: Neste artigo é apresentam-se visões distintas da informação: o operador funcional de sistemas sociais ou uma dinâmica complexa.

Objetivo: Discutir questões da administração da informação para inovação em uma organização. Esta discussão é realizada a partir do estudo específico na Fundação CERTI - Centros de Referência em Tecnologias Inovadoras, vinculada a Universidade Federal de Santa Catarina.

Metodologia: Esta investigação combina observação participante, busca de documentos e entrevistas estruturadas.

Resultados: São apresentados resultados parciais da investigação sobre informação, comunicação e inovação tecnológica na Fundação CERTI, instituição de pesquisa e desenvolvimento tecnológico, vinculada à Universidade Federal de Santa Catarina com foco na inovação em negócios, produtos e serviços.

Conclusões: Sugere é que a Ciência da Informação pode contribuir com o desenvolvimento teórico e metodológico da administração da informação para inovação das organizações.
\end{abstract}

Palavras-chave: Habermas. Inovação. Administração da informação. Fundação CERTI. 


\section{INTRODUÇÃO}

Neste artigo o objetivo geral é discutir questões da administração da informação para inovação em uma organização. Esta discussão é realizada a partir do estudo específico na Fundação CERTI - Centros de Referência em Tecnologias Inovadoras, vinculada a Universidade Federal de Santa Catarina.

Apresentam-se visões distintas da informação: o operador funcional de sistemas sociais ou uma dinâmica complexa. O conceito de informação usado interfere profundamente na forma como se representa e analisa a sua organização e gestão. São discutidos conceitos de inovação e dos processos de inovação para destacar neles o papel da informação, como elemento constitutivo e dinamizador.

Machado, Lehmann e Araujo (2008, p. 159) caracterizam inovação como:

[...] a capacidade de uma organização de articular e mobilizar recursos (humanos, financeiros, materiais, etc.), para captar oportunidades e neutralizar ameaças (operacionais, mercadológicas, etc.); o processo de transformação de idéias (inovação) em soluções que atendam às necessidades existentes ou latentes; e o resultado de uma atividade criativa que resulta na forma de produtos, processos e sistemas, novos ou modificados (grifo nosso).

São apresentados resultados parciais da investigação sobre informação, comunicação e inovação tecnológica na Fundação CERTI, instituição de pesquisa e desenvolvimento tecnológico, vinculada à Universidade Federal de Santa Catarina com foco na inovação em negócios, produtos e serviços. Esta investigação combina observação participante, busca de documentos e entrevistas estruturadas.

\section{INFORMAÇÃO E INOVAÇÃO}

Ao responder a indagação "do que falamos quando se fala de informação", Gonzalez de Gómez (2000) afirma tratar-se de um termo flutuante que, tal como o de democracia, produz diferentes efeitos de sentido em diferentes contextos. Informação, como construção e sintoma da sociedade contemporânea, designa algo que se desdobra em vários planos de realização - todos eles transcendidos por valores semânticos e quadros normativos, da ordem do ideacional, e ancorados no solo de sua inscrição ou manifestação, da ordem do visível e do temporal. 
Gonzalez de Gomez (2008) observa que a informação tem para Habermas uma dupla ancoragem - socio-cognitiva e instrumental-estratégica. Por um lado, a informação está ancorada naquela temporalidade que atrela corpo e cultura numa configuração diferenciada e permite a abertura de múltiplas perspectivas sobre o mundo. Associada a algumas das plurais possibilidades heurísticas das ações - cotidianas e especializadas - a informação designa uma diferença que se instala nas experiências de confronto entre nossas expectativas prévias e do que acontece em nossas relações atuais com o mundo. Por outro lado, a informação, enquanto codificada, reconstitui-se através dos meios, nas zonas de trocas e negociação entre os sistemas e os mundos da vida - mediação porém constituída numa relação histórica e não "lógica", plausível, então, de ambivalências e de transformações.

A informação designa uma instância de constante reabertura das relações entre o mundo da vida e o mundo. A informação é considerada neste caso como constitutiva dos processos de objetivação nos contextos da experiência e da ação. Nessas dinâmicas da informação acontece a manifestação da alteridade, do que surpreende, e como tal, ela faz parte das condições da aprendizagem e dos desafios à imaginação lingüística (GONZALEZ DE GOMEZ, 2008).

A informação, enquanto codificada e imersa nos meios, opera no dominio dos sistemas - da administração, da economia e do mercado -, em exercícios funcionaisinstrumentais, e nas zonas de intermediação entre o sistema e os mundos da vida. A informação, mediatizada, ficaria associada ao problema da constituição do vínculo social, nas sociedades contemporâneas: nas situações em que a integração social, comunicativa, é substituída pela integração estabelecida por meios (GONZALEZ DE GOMEZ, 2008).

A pesquisa do termo "innovation" realizada na base de dados Library and Information Science Abstracts - LISA identifica cento e noventa e dois registros de artigos indexados nos últimos 30 anos. A base de dados LISA é desenvolvida pela Proquest CSA, e indexa atualmente mais de quatrocentos e quarenta periódicos publicados em sessenta e oito países.

A Figura 1 apresenta uma classificação hierárquica ou dendograma dos descritores dos cento e noventa e dois artigos encontrados na base LISA. Os principais descritores encontrados são: inovação, gestão de pessoas, gestão do conhecimento, desenvolvimento de produtos, organizações, cooperação, tecnologia de informação, 
apropriação tecnológica, softwares e Internet.

Figura 1 - Classificação hierárquica de descritores

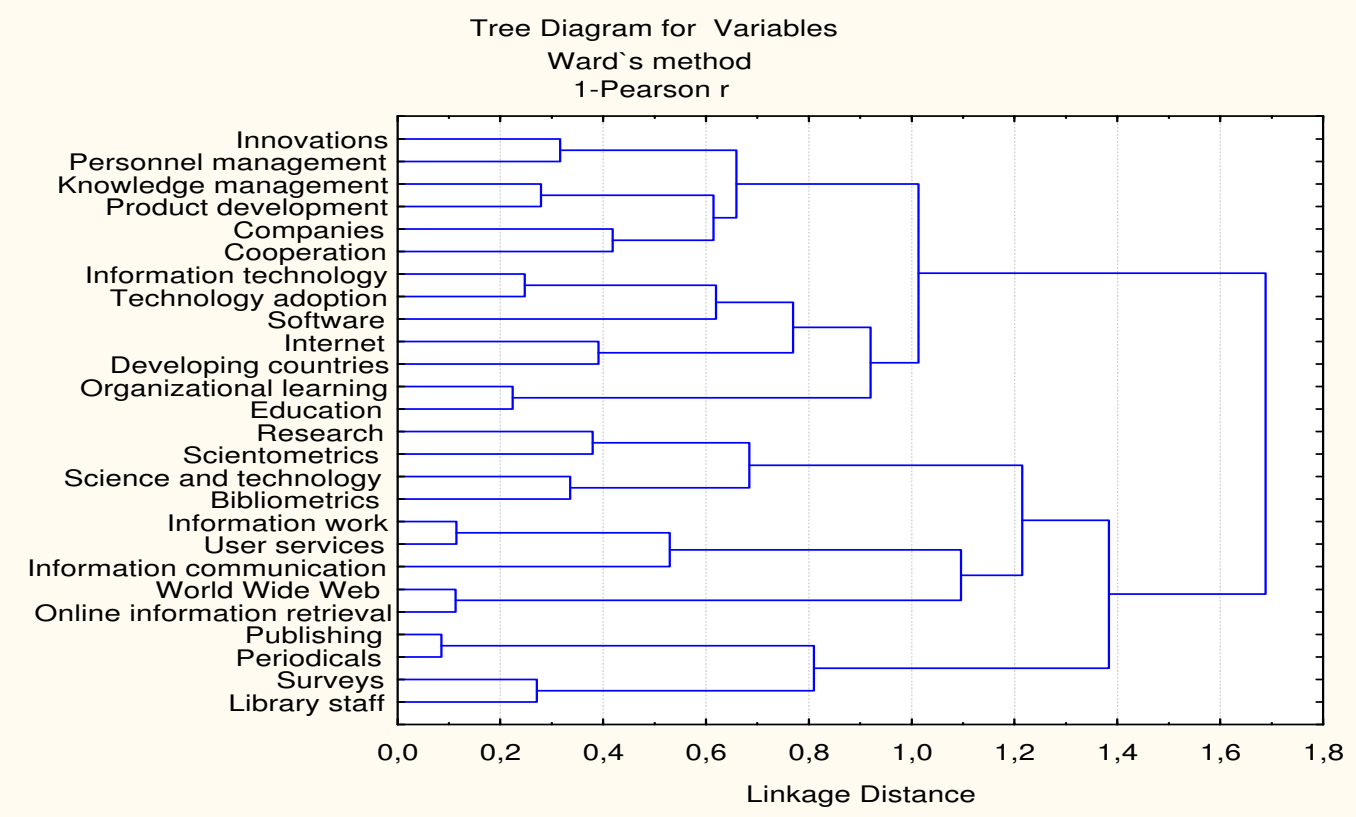

Fonte: Os autores.

A Figura 2 mostra a classificação não hierárquica dos descritores dos mesmos cento e noventa e dois artigos encontrados na base LISA. Esta classificação sinaliza a formação de quatro agregados (clusters) de descritores. O primeiro agregado compreende: gestão do conhecimento, tecnologia de informação, apropriação tecnológica, desenvolvimento de produtos e Internet.

O segundo agregado compreende: cooperação, educação, gestão de pessoas, Internet, softwares e recuperação de informação on line. O terceiro cluster inclui: trabalho com informação, investigações, publicação, bibliotecas, serviços de usuários e revistas acadêmicas. O quarto cluster inclui: cientometria, ciência e tecnologia, pesquisa e bibliometria. 
Figura 2 - Classificação não hierárquica de descritores

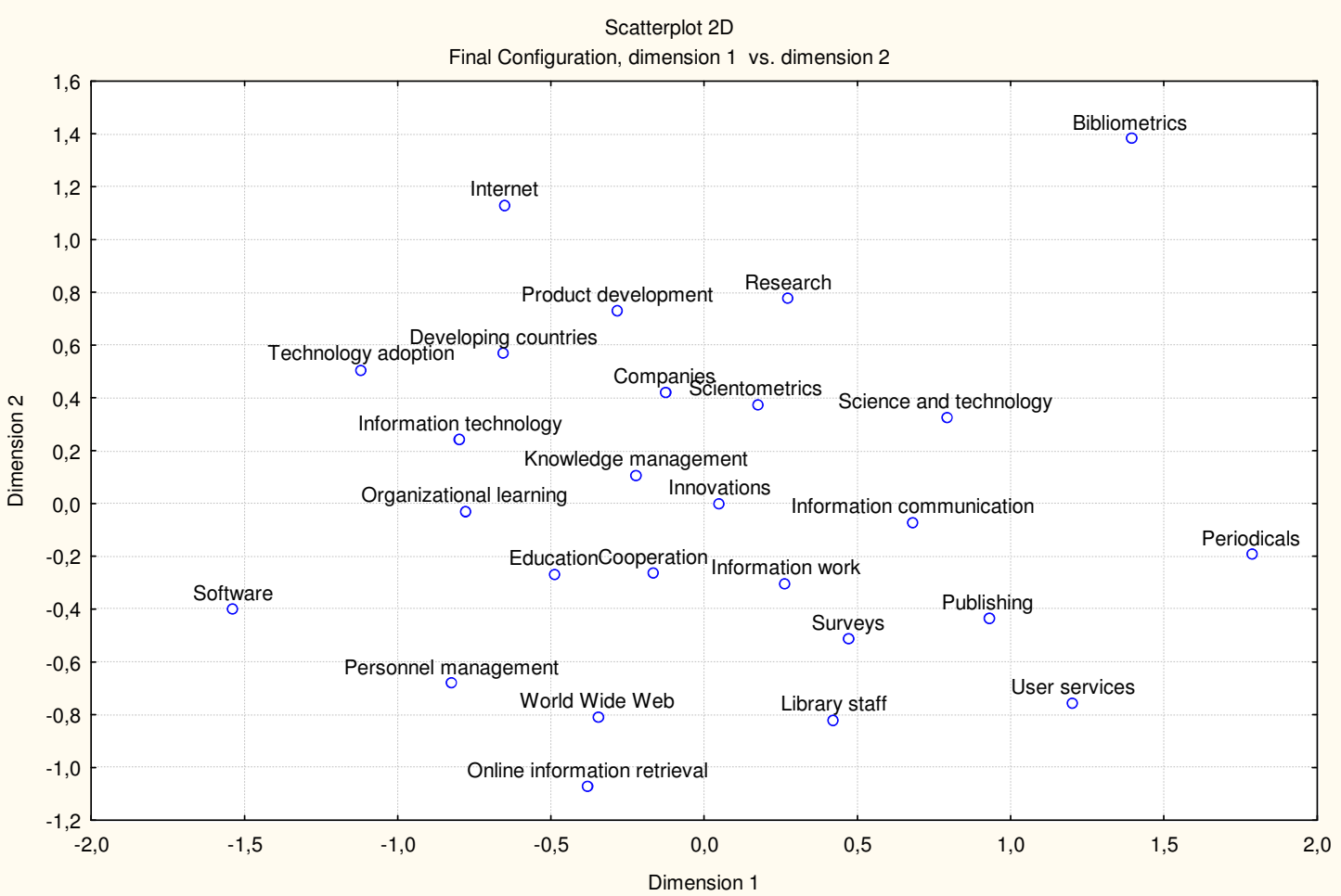

Fonte: Os autores.

Estes quatro agregados são importantes indicações da atual produção sobre informação e inovação tecnológica em parte da Ciência da Informação. Estas indicações são particularmente pertinentes para orientar revisões de literatura amplas que tenham por foco e interesse às abordagens instrumental e sistêmico-funcional predominantes nesta área do conhecimento.

A inovação é, de acordo com o Manual de Oslo, um processo complexo e a gama de atividades exigida para a inovação em uma organização pode variar consideravelmente. O desenvolvimento dentro da própria organização de um produto radicalmente diferente e sofisticado para o mercado de massa pode envolver muitas etapas mais do que a introdução de processo aprimorado resultante de tecnologia incorporada em uma máquina pré-programada adquirida para tal fim (ORGANIZAÇÃO PARA A COOPERAÇÃO E DESENVOLVIMENTO ECONÓMICO, 2004).

Um ponto de partida para análise da atividade de inovação, segundo o Manual de Oslo, pode ser a pesquisa e desenvolvimento, que assume uma variedade de formas funcionais relacionadas com a solução de problemas. Argumenta-se frequentemente, por exemplo, que as organizações precisam fazer pesquisa para reconhecer, usar e, por conseguinte, adotar, tecnologias que tenham sido desenvolvidas em outro local 
(ORGANIZAÇÃO PARA A COOPERAÇÃO E DESENVOLVIMENTO ECONÓMICO, 2004).

Schumpeter (1961) afirma que são cinco os tipos básicos de inovação: 1) desenvolvimento de um novo produto, ou de uma nova tecnologia de um bem existente; 2) desenvolvimento de um método de produção, ou de uma nova logística comercial; 3)desenvolvimento de um novo mercado; 4) desenvolvimento de novas fontes de suprimento das matérias-primas ou produtos semi-industrializados; 5) desenvolvimento de uma nova organização industrial, como a criação ou a fragmentação de uma posição de monopólio.

A inovação tecnológica é movida pela geração de conhecimento e sua aplicação na geração de novos produtos e processos que possam trazer vantagens competitivas para as empresas. Dosi (1984) destaca três características econômicas relevantes para a análise da inovação tecnológica: a) grau de oportunidade tecnológica - oportunidade de introdução de avanços tecnológicos rentáveis; b) cumulatividade nas capacidades tecnológicas - inerente aos padrões de inovações e à capacidade de inovar das empresas; e c) apropriação privada das vantagens advindas da inovação - retorno econômico do progresso técnico. As três características condicionam fortemente o processo de inovação e são utilizadas pelas empresas como fatores para proteger eventuais vantagens competitivas e erguer barreiras aos concorrentes.

Lemos (1999) observa que uma organização não inova sozinha, pois as fontes de informações, conhecimentos e inovação podem ser localizar tanto dentro, como fora dela. O processo de inovação é, portanto, um processo interativo, realizado com a contribuição de variados agentes econômicos e sociais que possuem diferentes tipos de informações e conhecimentos.

Gorz (2005) comenta que a pesquisa privada nas organizações quase sempre tem como objetivo principal permitir que quem a realiza possa erguer um monopólio do conhecimento que proporcione rendimento exclusivo. O rendimento esperado conta mais do que o uso social do conhecimento produzido. Com investimentos em inovações e custosas campanhas de propaganda, toda empresa visa chegar antes das outras a consolidação de posição monopolista. 


\section{ADMINISTRAÇÃO DA INOVAÇÃO EM ORGANIZAÇÕES}

A grande contribuição de Luhmann é renovar a teoria dos sistemas, baseada numa mudança paradigmática: passar da distinção do todo e das partes, para a distinção de sistema e entorno, tendo como referência o conceito de complexidade. Entre a extrema complexidade do mundo e a capacidade de entendimento humana existe uma lacuna. Os sistemas sociais assumem a sua função, assumindo a tarefa de redução de complexidade (NEVES; NEVES, 2006).

Os sistemas sociais agem para reduzir a complexidade do mundo em dois planos: por meio da estruturação ou redução da complexidade interna e através da seletividade ou redução da complexidade externa. É por meio da comunicação que se seleciona a informação disponível no ambiente. Os sistemas sociais usam a comunicação como seu particular modo de reprodução autopoiética (LUHMANN, 1984).

Lyytinien (1987) afirma que os sistemas de informação são uma instituição comunicativa. A comunicação através do sistema de informação cria, controla e dá sustentação às interações sociais num contexto organizacional. $O$ caráter específico de um sistema de informação como meio de comunicação deriva da natureza formal de sua linguagem e dos modos preestabelecidos de seu uso.

Gonzalez de Gómez (2004) comenta que os estudos de Lyytinien, que introduziriam conceitos da Teoria do Agir Comunicativo de Habermas ao domínio da concepção de sistemas, além de colocar em relevo o caráter comunicacional do sistema de informação, introduzem elementos críticos nas visões racionalistas de transparência do sistema. No contexto, a noção de agir comunicativo é um desdobramento da intuição segundo a qual o telos do entendimento habita na linguagem. Habermas propõe o empreendimento intersubjetivo através da discussão, que deriva da concepção construtivista da aprendizagem, na medida em que compreende a formação discursiva da vontade como forma de reflexão do agir comunicativo e exige a passagem do agir estratégico para a discussão.

A teoria da discussão de Habermas (2004) põe em cena a noção de procedimentos e pressupostos da comunicação para formação democrática da opinião e da vontade, funcionando como importantes escoadouros da racionalização discursiva das decisões na administração de organizações. Racionalização significa mais do que mera legitimação, mas menos do que a própria ação de constituir o poder, o qual administrativamente 
disponível modifica seu estado de mero agregado, desde que a formação democrática da vontade não se exerça apenas no controle posterior do exercício do poder, mas que também o programe de uma maneira ou de outra o exercício do poder.

A ética da discussão desenvolvida por Habermas (1989) não dá orientação de conteúdo, mas sim o procedimento rico em pressupostos que deve garantir a imparcialidade da formação de juízo. O discurso prático é um processo, não para a produção de normas justificadas, mas para o exame da validade de normas consideradas hipoteticamente. É só com este procedimento que a ética da discussão se diferencia de outras éticas cognitivistas, universalistas e formalistas. Todos os conteúdos, mesmo os concernentes a normas de ação, não importa quão fundamentais estas sejam, têm de ser colocados na dependência de discursos reais.

A discussão prática acontece quando o modo de agir carece de fundamentação de natureza coletiva e os membros da organização têm que chegar a uma decisão comum sobre suas ações, e têm que tentar convencer-se mutuamente de que é interessante para cada um que todos ajam assim. Neste processo cada um indica ao outro as razões por que ele pode querer que um modo de ação seja tornado socialmente obrigatório. Cada pessoa tem de se convencer de que a norma proposta é igualmente boa para todos. A discussão pode criar argumentos que legitimem a decisão de orientações para a ação coletiva e acordos práticos (HABERMAS, 1989).

A discussão conta com a intersubjetividade presente nos processos de entendimento que se cumprem, por um lado, na forma institucionalizada de aconselhamento nas organizações, e, por outro, nas redes de comunicação. As estruturas de comunicação da opinião compõem rede amplamente disseminada de sensores que reagem à pressão de situações-problema nas organizações. A opinião transformada em poder comunicativo segundo procedimentos democráticos não pode "dominar", mas apenas direcionar o uso do poder administrado para determinados canais. $\mathrm{O}$ discurso argumentativo imuniza ações de repressão e desigualdades, apresenta-se como forma de comunicação aproximada das condições ideais de cooperação.

A busca constante pela inovação, por meio da criação e desenvolvimento de novos produtos e processos, diversificação, qualidade e absorção de tecnologias avançadas, é indispensável para assegurar elevados níveis de eficiência, produtividade e competitividade das organizações. Isso implica acumulação constante de conhecimentos e capacitação tecnológica contínua. Nesse contexto, insere-se a aprendizagem 
organizacional (aprendizado contínuo e interativo), configurando-se como o processo mais importante para o desenvolvimento da inovação tecnológica (TOMAÉL; ALCARÁ; DI CHIARA, 2005).

As organizações que cultivam a aprendizagem organizacional são organizações com habilidades para criar, adquirir, transferir conhecimentos e modificar comportamentos, refletindo o novo conhecimento e o novo insight. As organizações de aprendem possuem habilidades em cinco principais atividades: resolução sistemática de problemas, experimentação de novas abordagens, aprendizado com base na própria experiência e história passada, aprendizado por meio de experiências e melhores práticas de outros e a transferência do conhecimento de forma rápida e eficiente por toda a organização (TOMAÉL; ALCARÁ; DI CHIARA, 2005).

Knox (2002) enumera quatro aspectos que sustentam uma organização inovadora: a cultura e o clima organizacional; capacidades e habilidades de gerenciamento; controle e estrutura organizacional; e novos produtos e desenvolvimento de processos. $\mathrm{O}$ autor salienta que a inovação contínua está baseada nas capacidades e atitudes das pessoas que trabalham na organização. Estas capacidades e atitudes dependem da cultura organizacional, que estimule o empreendedor individual e o trabalho em equipe (apud MACHADO; LEHMANN; ARAUJO, 2008).

Barbieri et al. (2004) destacam que existem fatores que condicionam a inovação. Os fatores são delimitados pelo modelo de gestão que poderá favorecer o surgimento de inovações. Eles argumentam que motivação, satisfação no trabalho, estímulo à criatividade, redução de conflitos entre gerências, liderança, comunicação interna, gestão de projetos de inovação, empreendedores internos, sistemas de recompensas e clima inovador são alguns temas relacionados com modelos de gestão que interferem em processos de inovação.

Barbieri et al. (2004) afirmam que é difícil manter um ritmo constante de inovações, mesmo de desenvolvimento ou incrementais. Eles sugerem que inovações tecnológicas ou organizacionais processam-se através de formas complexas, envolvendo atividades realizadas por pessoas dentro e fora das organizações. As condições para que operem de forma mais eficiente e eficaz podem ser conseguidas através da formulação e condução de modelos de gestão para o favorecimento e manutenção de um meio inovador interno, podendo, inclusive, gerar uma cultura de inovação.

Machado, Lehmann e Araujo (2008, p. 161) enuncia os fatores condicionantes do 
meio inovador interno: eficiência percebida com a inovação, incerteza sobre a inovação, escassez de recursos, padronização de procedimentos, grau de influência nas decisões, expectativas de prêmios e sanções; liderança do time de inovação, liberdade para expressar dúvidas e aprendizagem encorajada.

Arranjos organizacionais mais flexíveis demandam e facilitam maneiras de pensar que transcendem estreitos domínios profissionais, de serviço ou de setor. Considerando que muitas habilidades e recursos essenciais para a organização estão fora de suas fronteiras, e, portanto, fora do controle direto da administração, parcerias e alianças não devem mais ser vistas como opções, mas como uma necessidade (SILVEIRA, 2005).

Silveira (2005) afirma que a migração para um ambiente colaborativo com a prevalência de relacionamentos organizacionais pode ser considerada uma mudança de paradigma. O real desafio na construção e gestão de ambientes informacionais cooperativos é o compartilhamento de significados, uma vez que a informação - como o conteúdo da interação social - provê os materiais brutos a partir dos quais a "construção de significados" pode acontecer.

Barañano (2005, p. 59), ao estudar a gestão da inovação tecnológica em micro e pequenas empresas portuguesas, observa que:

[...] o sucesso da inovação tecnológica empresarial depende, em grande medida, de aspectos como a estrutura da força de trabalho, a estratégia, as alianças com outras empresas ou com universidades e, acima de tudo, a organização interna da empresa. O desenvolvimento de inovações tecnológicas está fortemente condicionado pela existência de um ambiente interno no qual as idéias criativas possam emergir, e ser aplicadas com eficácia e os conhecimentos quer tecnológicos, quer de gestão, possam ser acumulados.

Barañano (2005, p. 60) afirma que nenhum elemento isolado tem possibilidade de ser eficaz e, portanto, nenhuma ferramenta ou técnica de gestão cria e sustenta sozinho um ambiente propício a inovação. A inovação é um complexo processo sociológico e econômico que envolve uma teia extremamente intrincada de interações, tanto no interior da empresa como entre estas e o seu contexto econômico, técnico e social. É um conjunto de diferentes fatores inter-relacionados que devem funcionar para criar e reforçar o tipo de ambiente que facilita o sucesso da inovação tecnológica.

Estes fatores ou práticas de gestão podem agrupar-se em redor dos cinco eixos seguintes: 
(i) criação e manutenção de canais de comunicação fluidos, quer internos, quer externos;

(ii) atenção aos clientes atuais e potenciais, envolvendo-os no processo de inovação;

(iii) apoio explícito da alta gestão à inovação tecnológica;

(iv) disponibilidade de recursos humanos altamente qualificados e presença na organização de indivíduos que apóiem os projetos de inovação tecnológica, especialmente nos momentos críticos;

(v) criação e manutenção de uma estrutura organizacional flexível (BARAÑNANO, 2005, p. 61).

O sucesso dos processos de inovação requer a criação e a manutenção de fluidos canais de comunicação internos e externos. A implementação de inovações depende da combinação de diferentes tipos de conhecimentos, que habitualmente estão distribuídos entre as várias unidades organizacionais. Em conseqüência, para terem sucesso nos seus projetos de inovação, necessitam da cooperação entre as áreas de investigação, desenvolvimento, produção, marketing e finanças, de forma a permitir a contínua partilha de dados, de informação e de conhecimentos.

Albagli e Maciel (2004) afirmam que difusão e compartilhamento de informações e conhecimentos requerem a conexão entre os atores, com canais ou mecanismos de comunicação que propiciem fluxos de conhecimento e o aprendizado interativo. Referemse à existência de correlação entre presença de relações cooperativas, diversidade de mecanismos de comunicação entre agentes diferenciados e desempenho inovador das organizações. Observa-se que as organizações e agentes que cooperam introduzem maior número de inovações do que os que não cooperam e o grau de inovação aumenta com a variedade de parceiros que se comunicam entre si.

Baranãno (2005) considera que o sucesso dos processos de inovação requer como medida básica a criação e manutenção de múltiplos canais de comunicação abertos, bem como de complementar os habituais canais verticais de comunicação, com canais de comunicação horizontais e diagonais que liguem indivíduos localizados em diferentes unidades organizacionais. A fluidez da comunicação interna e, acima de tudo, a integração de todas as atividades, contribuem para o lançamento de inovações com sucesso, pois garante que todos os esforços apontem numa mesma direção.

\section{INFORMAÇÃO E INOVAÇÃO NA FUNDAÇÃO CERTI}

O estudo das relações entre informação, comunicação e inovação é desenvolvido 
na Fundação CERTI - Centros de Referência em Tecnologias Inovadoras, que é uma instituição independente de pesquisa e desenvolvimento tecnológico com foco na inovação em negócios, produtos e serviços. A CERTI é hoje referência em âmbito nacional e internacional pelo desenvolvimento de projetos inovadores que envolvem soluções de convergência digital, como a urna eletrônica brasileira, os terminais de automação bancária e terminais públicos de acesso à Internet.

Criada em 1984, por iniciativa de algumas empresas brasileiras, da Universidade Federal de Santa Catarina e dos Governos Federal e Estadual, a Fundação CERTI surge dentro do Labmetro - Laboratório de Metrologia do Departamento de Engenharia Mecânica da UFSC - Universidade Federal de Santa Catarina, e desde 1990 funciona em prédio próprio no campus da UFSC.

A partir desse mesmo ano a CERTI passa a atuar expressivamente na gestão da qualidade e produtividade, em conseqüência das grandes mudanças nas políticas econômicas e industriais do Brasil. A partir da década de 90, voltou-se à prestação de serviços metrológicos de alto nível, com ênfase na calibração, buscando desde cedo à ampla acreditação dos seus serviços laboratoriais junto ao INMETRO e organismos internacionais, como forma de contribuir para o fortalecimento da credibilidade da metrologia no país.

Em 1995 a incubadora da CERTI passa a operar no Parque Tecnológico Alfa em Florianópolis-SC, com a designação de CELTA - Centro Empresarial de Laboração de Tecnologias Avançadas. Em 1999 inaugura uma filial na cidade de Manaus para dar apoio às empresas de base tecnológica estabelecidas naquela região. Como instituição de ciência, tecnologia e inovação, a CERTI nasce direcionada para a pesquisa tecnológica aplicada. Para tanto, firma e amplia parcerias com universidades e centros de pesquisas do país e exterior, como a própria UFSC, o MIT (Massachusetts Institute of Technology), nos Estados Unidos e o PTB (Physikalisch Technische Bundesanstalt), na Alemanha.

Ao longo dos seus vinte e dois anos a Fundação CERTI tem focado suas ações na cadeia produtiva da tecnologia da informação, sistemas mecatrônicos, metrologia e garantia da qualidade, com uma atuação integrada de seus Centros de Referência, dos seus Laboratórios e de seus Institutos. Em função de demandas empresariais, a Fundação estabeleceu em Manaus e em Brasília institutos tecnológicos que atuam em áreas semelhantes e complementares, respectivamente, o Instituto CERTI Manaus e o Instituto Sapientia. 
No campo da pesquisa e desenvolvimento, a CERTI destaca-se ao longo dos anos nos campos da metrologia, no desenvolvimento e customização de projetos que envolvem a prototipagem e montagem de placas de circuitos eletrônicos com o diferencial de produção em séries pequenas, na Meca optoeletrônica, em sistema da qualidade e, mais recentemente, na área de gestão empresarial. Mais de seiscentas empresas e instituições de todo o Brasil beneficiam-se, anualmente, dos serviços tecnológicos, dos projetos de melhoria de processos, dos desenvolvimentos de produtos inovadores e dos empreendimentos tecnológicos desenvolvidos pelos Centros da Fundação CERTI.

A Fundação CERTI é formada por equipes com duzentos e vinte colaboradores, especializados em Universidades do Brasil e do exterior, que possuem amplo know-how em suas áreas de atuação. O valioso capital intelectual é considerado um fator-chave para alcançar os melhores resultados e manter a posição de destaque em Inovação, Ciência e Tecnologia.

A inovação pode advir da criação de novos processos nas organizações, quer processos produtivos novos para um produto, quer processos produtivos que possibilitam a criação de novos produtos. O processo inovador industrial deve gerar diferenças em preço, qualidade e singularidade. Ele parte de idéias e oportunidades para construir elementos do processo que assegura diferencial competitivo de domínio exclusivo da empresa. Eles usualmente implicam em recursos e no uso de saberes especializados avançados (Ver Figura 3).

O conceito de inovação usado na Fundação CERTI orienta suas ações para assegurar três condições: ter a gestão interna para promover a inovação; manter cooperação e parceria com outras empresas e instituições de pesquisa e desenvolvimento; e, por último, saber fazer uso de oportunidades de incentivos e financiamentos (FUNDAÇÃO CERTI, 2009).

Por outro lado, é muito difícil a organização desenvolver a multiplicidade de operações requeridas de forma autônoma. O conhecimento, as tecnologias e as operações associadas podem ser ou fortalecidas ou supridas pela cooperação com Instituições de Ciência, Tecnologia e Inovação, ou mesmo por outras empresas. Finalmente, para que o processo de inovação seja eficaz e efetivo, é fundamental uma boa gestão, de forma a diminuir riscos, aperfeiçoar o uso de recursos e aproveitar as oportunidades de parcerias e financiamentos existentes no Estado, no País e até no exterior (INOVA, 2007). 
Figura 3 - O processo industrial inovador na Fundação CERTI

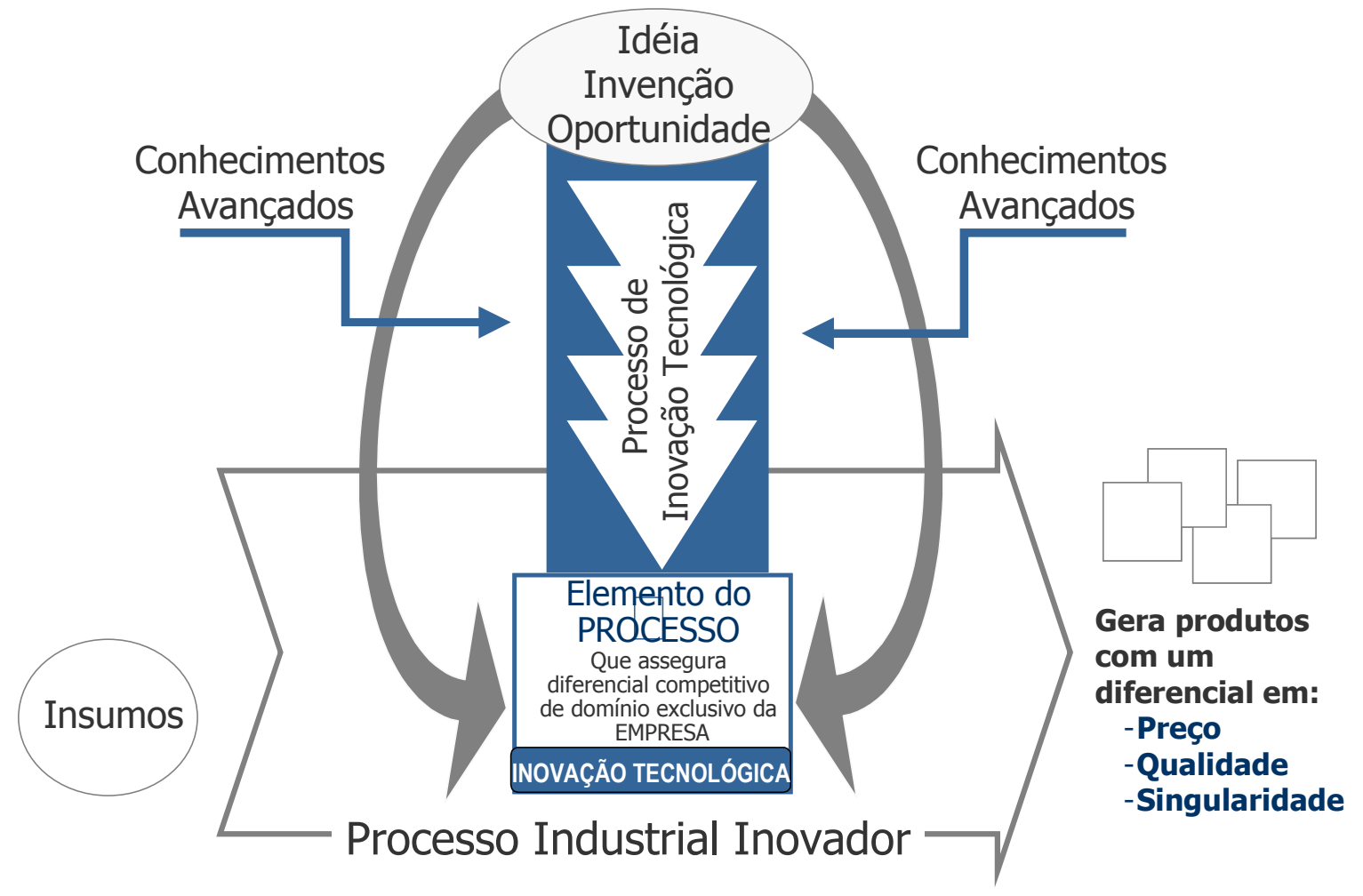

Fonte: Fundação CERTI (2007).

A partir de iniciativa cooperativa de fomento da inovação do Governo do Estado de Santa Catarina, a Fundação CERTI estabelece parceria com o INOVA- SC. Este programa público-privado tem como objetivo do programa proporcionar informações estratégicas e promover ações estruturantes em prol da dinâmica de inovação tecnológica nas empresas catarinenses, por meio da cooperação entre empresas, agentes de fomento e entidades geradoras de conhecimento e tecnologia, atuando de forma integrada e harmonizada (INOVA 2007).

No Ciclo de Inovação Tecnológica realizado pelo Instituto de Estudos Avançados da Universidade de São Paulo em 2006 a Fundação CERTI apresenta os desafios da gestão da inovação tecnológica (Figura 4). As diretrizes desta gestão da inovação são os seguintes: mínimo tempo e custo de desenvolvimento, qualidade adequada e inserção de conhecimentos avançados. 
Figura 4 - Os elementos chave do processo de inovação tecnológica

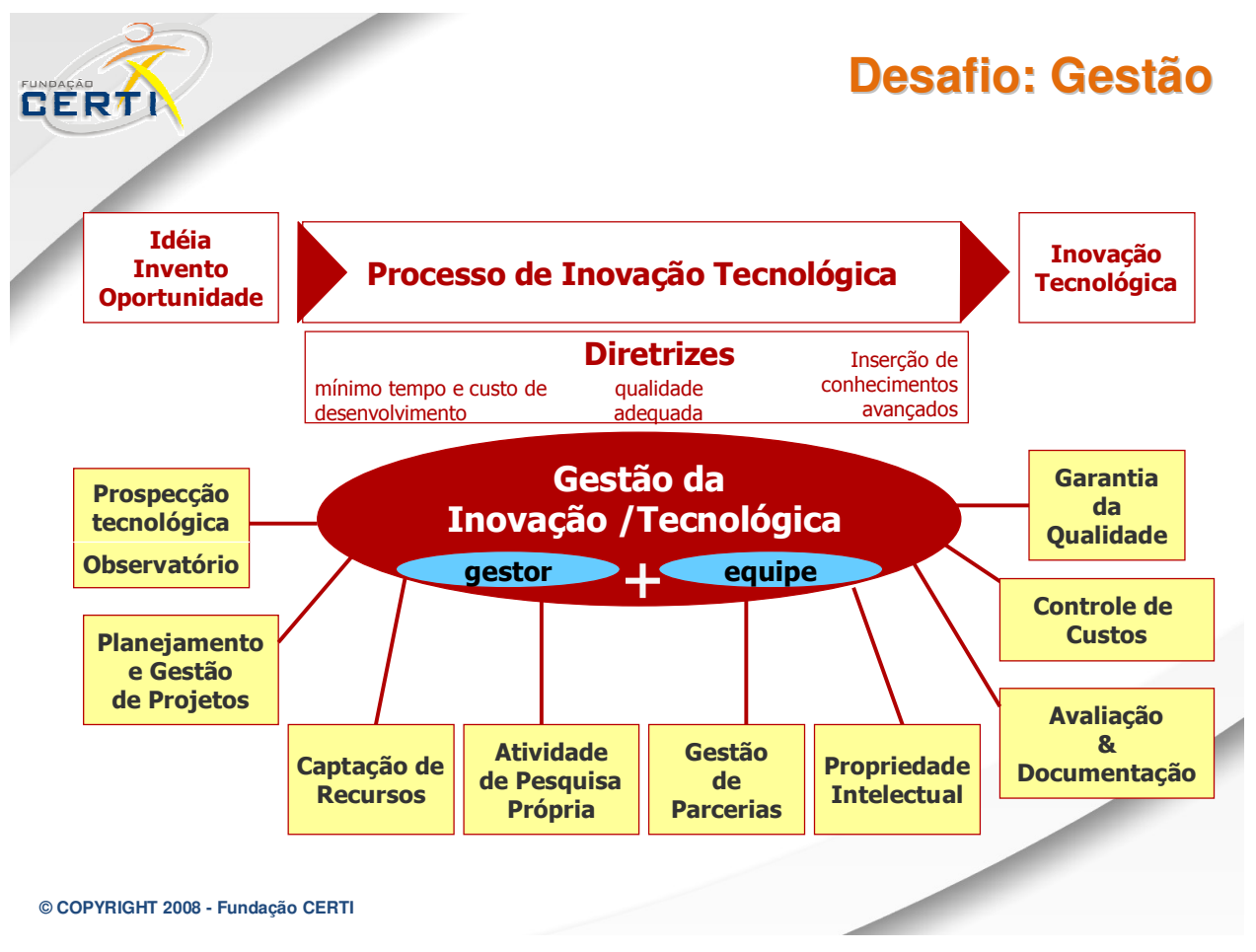

Fonte: Fundação CERTI (2007)

Os nove desafios da gestão do processo de inovação tecnológica sugeridos pela Fundação CERTI são os seguintes: prospecção tecnológica, atividade de pesquisa própria, captação de recursos, planejamento e gestão de projetos, gestão de parcerias, garantia da qualidade, controle de custos, propriedade intelectual, avaliação e documentação.

Em 2006 a Fundação CERTI teve aprovado pela FINEP - Financiadora de Estudos de Projetos um projeto para desenvolvimento da SINAPSE - Sistema de Gestão da Inovação Tecnológica para institutos promotores de ambientes de inovação. O objetivo geral do projeto é estruturar, aperfeiçoar e desenvolver um conjunto de sistemas de gestão e tecnologias da informação focada nos desafios e especificidades da gestão da inovação tecnológica em institutos que se propõe a atuar como produtores de ambientes de inovação dinâmicos e competitivos.

O projeto apresentado pela Fundação CERTI é desenvolvido em torno de algumas questões: 
- Como operar um instituto de tecnologia para desempenhar papel relevante na promoção de ambientes de inovação formados por novas empresas, empresas inovadoras estabelecidas, universidades e outros institutos?

- Quais práticas, ferramentas e sistemas de gestão de inovação tecnológica são necessários a criação de ambiente efetivamente sinérgico, criativo e competitivo?

- Como a atuação diferenciada de um instituto de tecnologia com parceiros e clientes pode oferecer novas perspectivas de sustentabilidade $e$ crescimento, baseadas na obtenção de royalties e na participação no capital de novas empresas de base tecnológica?

- Ë possível estabelecer no Brasil um verdadeiro cluster de inovação dinâmico e competitivo?

A Fundação CERTI vem ao longo da sua história desenvolvendo e aperfeiçoando os seus sistemas de gestão organizacional, de forma a cumprir adequadamente a sua missão de fornecer soluções inovadoras estratégicas e competitivas para seus clientes e para a sociedade. Na sua experiência a Fundação CERTI desenvolve, absorve e implanta práticas e sistemas que contribuem para o avanço da instituição. Ela tem obtido resultados e conquistas tanto no segmento empresarial como governamental.

O aprendizado acumulado da Fundação CERTI "a faz concluir que a única forma de um instituto sobreviver numa conjuntura global e nacional como a que vivemos atualmente é estruturar e fortalecer um ambiente de inovação dinâmico e competitivo, no qual o instituto tenha um papel de protagonista" (FUNDAÇÃO CERTI, 2006).

Assim, a organização precisa:

- praticar gestão tecnológica exemplar em seus processos e projetos;

- relacionar-se com outros institutos parceiros de forma inovadora e eficaz;

- trabalhar com seus clientes como um verdadeiro parceiro estratégico;

- induzir e apoiar a criação de empresas inovadoras a partir de seus projetos e de suas equipes;

- posicionar-se como grande elemento articulador e facilitador do ambiente de inovação em que está inserido. 


\section{CONSIDERAÇÕES FINAIS}

O que a investigação sugere é que a Ciência da Informação pode contribuir com o desenvolvimento teórico e metodológico da administração da informação para inovação das organizações. Cabe aqui pensar a informação como dinâmica organizacional que abre possibilidades para a criação, a melhoria e a inovação dos processos e produtos.

Assim, a administração da informação é mais do que uma racionalização funcional das ações de informação. A discussão dos processos em um sistema permanentemente problematizado pode ampliar as possibilidades de interação e colaboração entre os trabalhadores, destes com os gestores, e da organização com o seu entorno.

A colaboração interna e externa facilita não apenas o compartilhamento de informações e conhecimentos, mas também resulta deles. A colaboração viabiliza diálogos, e os diálogos viabilizam colaboração. As organizações não inovam sozinhas, mas sobre informações e conhecimentos acumulados dentro e fora delas. Cabe então pensar nas relações entre comunicação, colaboração e inovação.

A colaboração é condição para a inovação tecnológica, em primeiro lugar para que a informação possa fluir de modo não linear dentro das organizações e entre elas e o seu entorno. A comunicação pode contribuir com ideias e oportunidades para a inovação e na interação entre os colaboradores da organização, ao mesmo tempo em que difunde seus processos e produtos e cria condições para sua aceitação e uso.

\section{REFERÊNCIAS}

ALBAGLI, Sarita; MACIEL, Maria Lucia. Informação e conhecimento na inovação e no desenvolvimento local. Ciência da Informação, Brasília, v. 33, n. 3, p. 9-16, set./dez. 2004.

BARAÑANO, Ana Maria. Gestão da inovação tecnológica: estudo de cinco PMEs portuguesas. Revista Brasileira de Inovação, Rio de Janeiro, v.1, n.2, jan. /jun. 2005.

BARBIERI, Jose Carlos et al. Organizações inovadoras: estudos e casos brasileiros. Rio de Janeiro: Editora FGV, 2004.

DOSI, Giovanni. Technical change and industrial transformation. London: Macmillan, 1984. 
FUNDAÇÃO CERTI. Desafios do domínio do processo de inovação tecnológica nas empresas: gestão, cooperação e financiamento. In: ENCONTRO NACIONAL DE INOVAÇÃO EM MÁQUINAS, EQUIPAMENTOS E PROCESSOS, 2007, São Paulo. Anais... São Paulo: PROTEC, 2007. Disponível em: <http://www.protec.org.br/arquivos/eventos/download/CarlosAlbertoSchneider.pdf>. Acesso em: 22 maio 2009.

Fundação centros de referência em tecnologias inovadoras. Disponível em: <http://www.certi.org.br/>. Acesso em: 10 ago. 2008.

OBITEC: observatório da inovação tecnológica. Disponível em: <www.observatorio.certi.org.br>. Acesso em: 18 jan. 2009.

Relatório de atividades. Florianópolis: CERTI, 2006.

GONZÁLEZ DE GÓMEZ, Maria Nélida. Habermas, informação e argumentação. In: COLÓQUIO HABERMAS, 5., 2008, Florianópolis. Anais... Florianópolis: UFSC, 2008.

Novas fronteiras tecnológicas das ações de informação: questões e abordagens. Ciência da Informação, Brasília, v. 33, n. 1, p. 55-67, jan./abr. 2004. p. 7-31, 2000.

O caráter seletivo das ações de informação. Informare, Rio de Janeiro, v. 5, n. 2, GORZ, Andre. O imaterial: conhecimento, valor e capital. São Paulo: Annablume, 2005. HABERMAS, Jurgen. A Inclusão do outro: estudos de teoria política. 3. ed. São Paulo: Loyola, 2004. 1989.

Consciência moral e agir comunicativo. Rio de Janeiro: Tempo Brasileiro,

INOVA. Elementos do processo de inovação. 2007. Disponível em: $<w w$. inovasc.org.br/index.php?option=com_content\&view=article\&id=50\&ltemid $>$. Acesso em: 25 jan. 2009.

LEMOS, Cristina. Inovação na era do conhecimento. In: LASTRES, Helena M. M; ALBAGLI, Sarita. Informação e globalização na era do conhecimento. Rio de Janeiro: Campus, 1999. p. 122-144.

LUHMANN, Niklas. Soziale systeme: grundrisseiner allgemainem theorie, 1984.

LYYTINIEN, Kalle. Two views of information modeling. Information and Management, Amsterdam, n. 12, p. 9-19, 1987.

MACHADO, Denise Del Prá Netto; LEHMANN, Cristiane Arndt; ARAUJO, Bárbara de. Organização e cultura de inovação: elementos concretos e fatores percebidos. Revista Alcance, Itajaí, v. 15, n. 2, p. 152-168, maio/ago. 2008. 
NEVES, Clarissa Eckert Baeta; NEVES, Fabrício Monteiro. O que há de complexo no mundo complexo? Niklas Luhmann e a Teoria dos Sistemas Sociais. Sociologias, Porto Alegre, v. 15, p. 182-207, 2006.

ORGANIZAÇÃO PARA A COOPERAÇÃO E DESENVOLVIMENTO ECONÓMICO. Manual de Oslo: proposta de diretrizes para coleta e interpretação de dados sobre inovação tecnológica. Paris: OCDE, 2004.

SCHUMPETER, Joseph. Capitalismo, socialismo e democracia. Rio de Janeiro: Fundo de Cultura, 1961.

\section{SILVEIRA, Sergio Amadeo. A mobilização colaborativa e a teoria da propriedade do} bem intangível. Tese (Doutorado em Ciência Política) - Universidade de São Paulo, São Paulo, 2005. Disponível em: <http://twiki.softwarelivre.org/bin/view/TeseSA/WebHome>. Acesso em: 21 abr. 2009.

TOMAÉL, Maria Inês; ALCARÁ, Adriana Rosecler, DI CHIARA, Ivone Guerreiro. Das redes sociais à inovação. Ciência da Informação, Brasília, v. 34, n. 2, p. 93-104, maio/ago. 2005.

\section{Title}

Information management for innovation in an organization

\section{Abstract}

Introduction: This paper presents different views of information: the operator functional social systems or complex dynamics.

Objective: Discuss the management of information for innovation in an organization. This discussion is made from the specific study in CERTI Foundation - Reference Centers for Innovative Technologies, linked to the Federal University of Santa Catarina.

Methodology: This research combines participant observation, document search and structured interviews.

Results: We present partial results of research on information, communication and technological innovation in the CERTI Foundation, research institution and technological development, linked to the Federal University of Santa Catarina with a focus on business innovation, products and services.

Conclusions: Suggests that information science can contribute to theoretical and methodological development of information management for innovation in organizations.

Keywords: Habermas. Innovation. Information Administration. Fundação CERTI.

\section{Título}

Gestión de la información para la innovación en una organización

Resumen 
Introducción: Este trabajo presenta diferentes puntos de vista de la información: los sistemas sociales funcionales operador o dinámicas complejas.

Objetivo: Discutir el manejo de la información para la innovación en una organización. Este análisis se realiza desde el estudio específico de la Fundación CERTI - Centros de Referencia para las tecnologías innovadoras, vinculadas a la Universidad Federal de Santa Catarina.

Metodología: Esta investigación combina la observación participante, la búsqueda de documentos y entrevistas estructuradas.

Resultados: Se presentan los resultados parciales de la investigación sobre la información, la comunicación y la innovación tecnológica en la Fundación CERTI, institución de investigación y desarrollo tecnológico, vinculado a la Universidad Federal de Santa Catarina, con un enfoque en la innovación empresarial, los productos y los servicios.

Conclusiones: Sugiere que la informática puede contribuir al desarrollo teórico y metodológico de la gestión de la información para la innovación en las organizaciones.

Palabras clave: Habermas. Innovación. Information Administration. Fundação CERTI.

Recebido em: 10.09.2013

Aceito em: 30.11.2013. 